\title{
A social licence for the sharing economy
}

Keywords - sharing economy; social licence; acceptance; trust; resilience; systems thinking

\begin{abstract}
The emergence of community concerns around a range of sharing economy platforms have led to calls for more research into the so-called "dark side" of the sharing economy, including the development and application of analytical frameworks. In this article, we present one such framework based around social licence to operate (SLO), a concept that has been applied most extensively in the mining, forestry and energy sectors. We argue that, despite requiring some adaptations and refinements for application to the sharing economy context, social licence is a relevant and suitable concept for analysing community acceptance of sharing economy platforms and provides an opportunity for mutual learning between different sectors. We present a Sharing Economy SLO Framework and outline a research agenda that includes defining communities of interest and place that are affected by sharing economy practices, analysing the complex relationships between social acceptance and regulatory requirements, identifying and measuring key variables that determine SLO, and developing strategies for building and maintaining SLO for sharing economy practices.
\end{abstract}

\section{Introduction}

Technological innovations involving digital online platforms for the exchange of goods and services between peers has enabled the emergence of the so-called "sharing economy" (Belk, 2014), which is experiencing rapid growth as it is heads towards a forecast global economic value of USD335 billion by 2025 (Yaraghi and Ravi, 2017). While definitions vary, at its 
core the sharing economy involves accessing rather than owning resources, exchange facilitated by digital platforms, and a community-based dimension rooted in the formation of new social connections and shared purpose (Acquier et al., 2017). However, while sharing economy platforms have the potential to create new social connections and build communities, this does not necessarily mean that the exchange practices they facilitate will be accepted by all communities impacted by them. Increasing awareness of this point has led to calls for more academic research into the so-called "dark side" of the sharing economy (Breidbach and Brodie, 2017; Murillo et al., 2017) and the application of analytical frameworks to these emerging issues (Frenken and Schor, 2017).

To provide some examples, Airbnb has emerged as a key focal point for the concerns of local residents in Barcelona about overtourism (Gutiérrez et al., 2017), including street protests in August 2017 (Independent, 2017). A month later in the UK, Transport for London declined to renew the regulatory licence of the ride-sharing platform Uber, citing "a lack of corporate responsibility in relation to a number of issues which have potential public safety and security implications" (Transport for London, 2017), including the reporting of serious criminal offences. In the same month, an Australian Senate committee raised concerns about pay rates and conditions for "gig economy" platforms where users bid for work (The Senate Education and Employment References Committee, 2017), including Sydney-based Airtasker, which has also faced union criticism for "allowing minimum industry standards to be completely eroded" (UnionsNSW, 2016, p. 7). More recently, Australia has witnessed disquiet around a very different example of the "sharing economy": dockless bike-share schemes, with concerns raised around bicycles being left in inappropriate locations. For example: 
"I think it's been clear the operators are not cleaning up their act... We're not happy with what they're doing. Residents are not happy with what they're doing” - John Wakefield, Mayor of Waverley Council (Sydney), March 2018 (ABC News, 2018)

In this article, we present a specific framework for analysing community acceptance of emerging practices such as those described above, social licence to operate (SLO), and evaluate its applicability to the sharing economy. Our choice of SLO as an analytical framework stems from a realisation that, while the use of online engagement platforms to access goods and services is relatively new, the issue of affected communities choosing to accept or reject emerging industry practices is not. Mining and forestry businesses have long had to contend with a diverse range of responses from local communities, and it is in these contexts that the SLO concept first emerged in the 1990s (Edwards et al., 2016; Franks et al., 2014; Prno and Slocombe, 2014). Over the past two decades, SLO has been applied to a diverse range of contexts and SLO frameworks have been developed that emphasise factors such as distributional fairness, procedural fairness, governance, adaptability and trust (Baumber, 2018; Dare et al., 2014; Hall et al., 2013; Zhang et al., 2015).

There are at least two examples of the term "social licence" being applied to sharing economy activities in academic papers. Cohen and Kietzmann (2014) explore ways for ridesharing platforms to enhance social licence, while Stanford (2017) highlights the risk that "gig work" platforms like Uber and Airtasker could lose it. However, neither article attempts to define social licence or to draw on the history of academic research into the concept over the past two decades in mining, forestry and other sectors. Our objectives in this article are to engage with this history, to assesses the applicability of the SLO concept to the sharing 
economy, to propose a framework for analysing SLO in the sharing economy, and to outline an agenda for future research.

\section{Conceptualising the sharing economy}

The four examples of Airbnb, Uber, Airtasker and share-bikes provided in the introduction highlight the diverse range of practices and contexts to which the term "sharing economy" can be applied. We recognise that some readers may dispute that some or even all of these examples should be classified as sharing economy. However, given that our evaluation of the SLO concept may have implications for how the sharing economy is defined, we don't wish to pre-empt our results by adopting an overly restrictive definition of the sharing economy at this stage. Instead, we follow the approach of Acquier et al. (2017) in viewing the sharing economy as an umbrella term and a contested space.

The challenge of defining and putting boundaries around the sharing economy has been highlighted not only by Acquier et al. (2017) but also in other recent reviews by Breidbach and Brodie (2017) and Frenken and Schor (2017). Acquier et al. (2017) conceive of the sharing economy as three overlapping "organising cores", which they term the "access economy", "platform economy" and "community-based economy" (Figure 1). These three foundations of the sharing economy broadly reflect the arguments of Belk (2014) that sharing implies temporary access to goods or services rather than ownership (i.e. access economy), that the emergence of new sharing practices has been driven by internet-based platforms (i.e.

platform economy) and that the term "sharing" implies some sense of community rather than simply seeking to maximise economic value (i.e. community-based economy). 


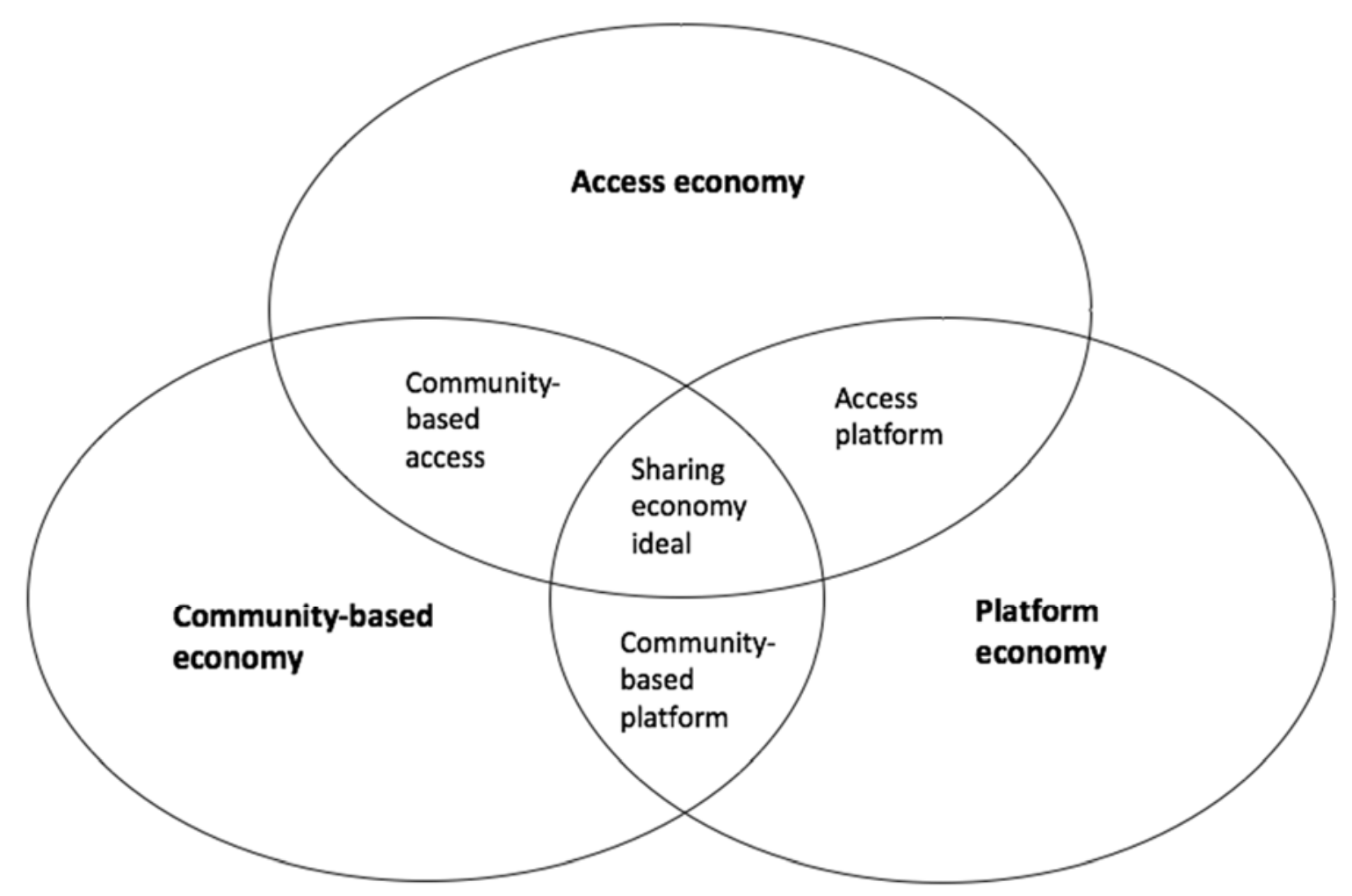

Figure 1: Three organising cores of the sharing economy with areas of overlap. Redrawn from Acquier et al. (2017).

While Acquier et al. (2017) regard the intersection of the three organising cores to represent a "sharing economy ideal", they recognise that sharing economy language is often applied to examples that lie outside this overlap zone. Furthermore, the definitions they apply to each of the organising cores are themselves contested. For example, Acquier et al. (2017) require assets be "underutilized" to qualify as part of the access economy, a view which is shared by Frenken and Schor (2017) and Cusumano (2015), but not by Breidbach and Brodie (2017). Conversely, Acquier et al. (2017) diverge from Frenken and Schor (2017) by including skillsharing alongside the sharing of resources under their model. For Frenken and Schor (2017), the sharing economy is restricted to physical goods, with skill-sharing classed instead as "ondemand" or "gig" economy. 
In relation to the platform economy core, Acquier et al. (2017) follow Cannon and Summers (2014) and Hamari et al. (2015) in requiring that exchanges be between "peers". Other authors use terms such as "individuals" (Cusumano, 2015) or "interdependent economic actors" (Breidbach and Brodie, 2017), which can have different connotations to "peers". This has implications for examples such as Sydney's bike-share schemes, which have employed sharing terminology (Figure 2), but otherwise resemble more traditional hire services rather than "peer-to-peer" platforms. Belk (2014) classifies activities of this nature as "pseudosharing".

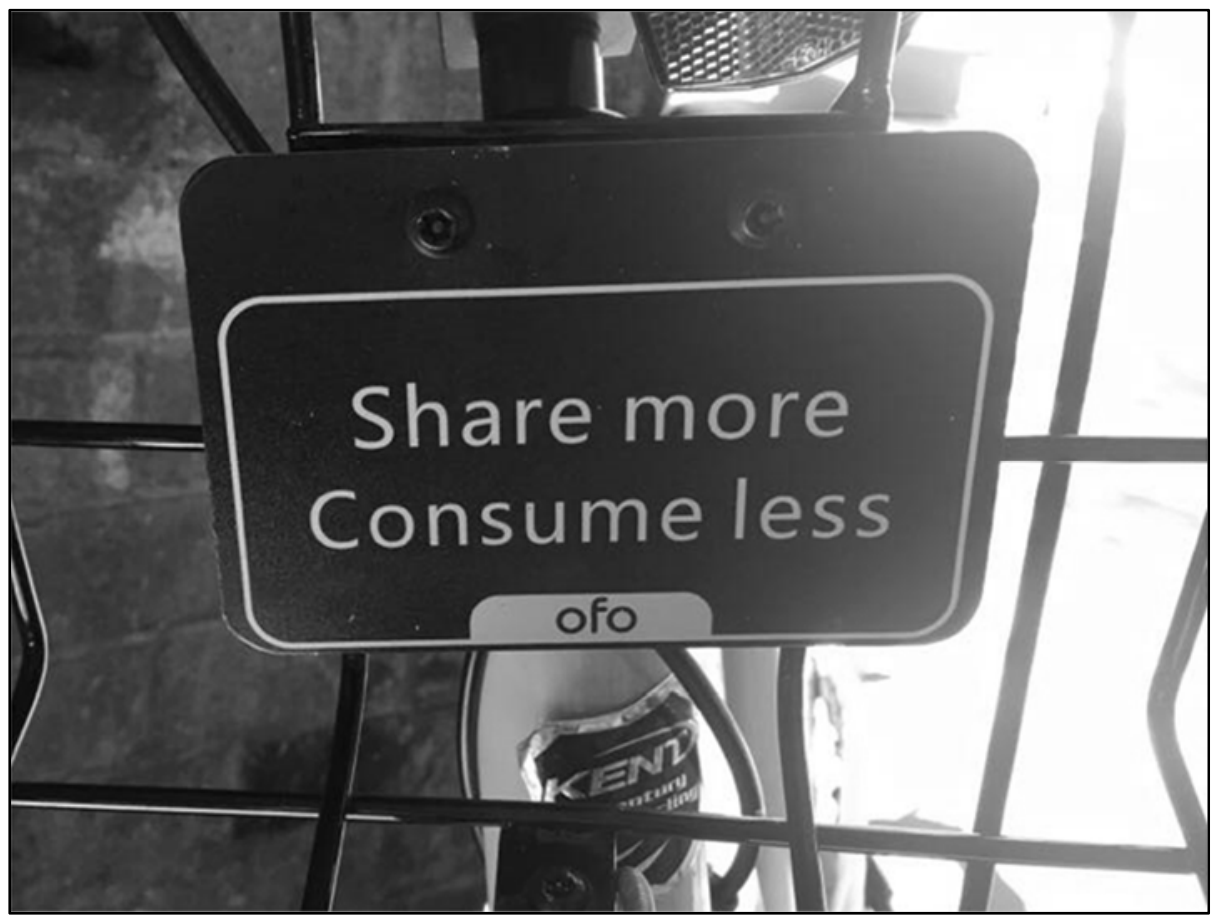

Figure 2: Bike-sharing company slogan photographed in Sydney, Australia in March 2018.

In relation to the "community-based" dimension of the sharing economy, Acquier et al. (2017) argue this requires a consideration of the types of interactions involved (i.e. non- 
contractual, non-hierarchical or non-monetized rather than traditional economic exchanges) as well as whether there is a shared purpose behind the exchange. The shared purpose may be to create social bonding or achieve a social mission, such as enhanced sustainability by using local or underutilised resources (Botsman and Rogers, 2010; Demailly, 2014; Heinrichs, 2013). Using shared purpose to define the community-based economy allows for money to change hands provided that the exchange is not solely about profit. This represents a kind of middle ground approach between that of Belk (2014), who argues that "true sharing" must be free of profit motives and expectations of reciprocity, and Breidbach and Brodie (2017), who regard monetary rewards for the sharing of resources to be one of the central tenets of the sharing economy.

For the purposes of this article, we take a broad view regarding which activities qualify as part of the access, platform and community-based economies. For the access economy, we include the sharing of skills (Acquier et al., 2017) rather than just physical resources (Frenken and Schor 2017). For the platform economy, we allow for exchange between "interdependent economic actors" (Breidbach and Brodie, 2017) rather than strictly "peers" (Cannon and Summers, 2014; Hamari et al. 2015). In relation to the community-based economy, we allow for monetary exchange and profit-making within the sharing economy (Breidbach and Brodie 2017) as long as there is some form of shared purpose motivating the exchange (Acquier et al., 2017).

In this article, we focus most closely on the community-based dimension of the sharing economy, as the SLO concept relates to "the ongoing acceptance or approval of an operation by those local community stakeholders who are affected by it" (Moffat et al., 2016). This requires careful consideration of who is part of an affected community and what makes them 
a community. In addition, the sharing economy presents an opportunity to expand and reconceptualise SLO due to the potential for digital, online platforms to create new types of community bonds based on shared interests rather than physical proximity (Acquier et al., 2017). As similar debates around "communities of place" versus "communities of interest" have also emerged in relation to the SLO concept (Dare et al., 2014; Ford and Williams, 2016), bringing these concepts together presents an opportunity to enhance our understanding of community around both the sharing economy and SLO. In the following section, we explore some of the issues that have emerged in attempting to define and conceptualise social licence to operate, before evaluating its relevance to the sharing economy.

\section{What is a "social licence to operate"?}

Social licence to operate (SLO) provides a way of both conceptualising and strategically building community acceptance or approval for new activities or practices that goes beyond the requirements of a formal regulatory process. Over the past two decades, it has been applied to a diverse range of land use activities, including mining (Cooney, 2017), forestry (Edwards et al., 2016), wind farms (Hall, 2014), cotton farming (Roth, 2011), energy cropping (Baumber, 2018), the creation of protected areas (Voyer et al., 2015) and, to a more limited extent, to service industries such as finance (O'Brien et al., 2015) and education (Haynes, 2018).

While SLO definitions vary, they most frequently emphasise "ongoing acceptance" of a project or activity by a local community and other stakeholders (Thomson and Boutilier, 2011, p. 1779). At its core, social licence is based on an analogy with a regulatory licence. However, a social licence is distinguished from a regulatory licence by its informal and intangible nature, the fact that it is sourced from a local community rather than a government 
agency and the complex and uncertain processes by which it may be obtained, maintained, denied or lost (Joyce and Thomson, 2000; Moffat et al., 2016).

Notwithstanding the challenges in determining whether or not a social licence has been obtained for a particular activity, numerous researchers have pointed out the risks that can arise from failure to obtain one, or from losing one that was previously held. These risks can include increased operating costs for industry (Franks et al., 2014), increased regulatory restrictions on future developments (Hall et al., 2013) and/or the closure of operations (Franks et al., 2011). A loss of social licence does not automatically equate to a loss of regulatory approval, but, as highlighted by the Uber and bike-sharing examples we referred to in the introduction, a lack of community acceptance can increase pressure on governments to restrict activities and affect the economic viability of a company's operations. Conversely, a strongly-held social licence may reduce transaction costs and protect a business from government attempts to restrict their operations.

In the present article, we will argue that the SLO concept could help to better understand the breadth and depth of acceptance of sharing economy platforms by particular communities or community groups. It could also shed light on the key determinants of community acceptance and the capacity of these platforms to withstand disturbances such as the community opposition encountered by Airbnb in Barcelona or bike-share operators in Sydney. In turn, the SLO concept, including its associated frameworks, variables and methodologies, may be enriched through application to new activities with different characteristics to the mining, forestry, agriculture and energy-related activities to which it has been most commonly applied to date. 


\section{SLO frameworks}

\subsection{Characteristics of SLO}

While definitions vary, the key characteristics of the SLO concept are its intangible and informal nature, the analogy with a regulatory licence and the idea that is awarded or withheld by a "community" of some kind. Ford and Williams (2016) also argue that SLO can be distinguished from the broader, overlapping concept of social acceptability by the use of the licence metaphor and a principal focus on relationships between businesses and local communities rather than on relationships with regulators or consumers.

Because of the analogy with a formal regulatory licence, the SLO concept can evoke ideas of a clear process that must be followed, a set of conditions that must be met and a degree of certainty that the social licence provides to an activity's proponents (Ford and Williams, 2016). However, Thomson and Boutilier (2011) caution against attempts to define SLO as something permanent, arguing that SLO is "dynamic and nonpermanent because beliefs, opinions, and perceptions are subject to change as new information is acquired" (p. 1779). This highlights that social licence is not simply something that a proponent must obtain once, but is something that needs to be actively maintained over time.

Measuring and monitoring SLO can be challenging due to its intangible and informal nature, with some authors emphasising the difficultly or impossibility of such a task (Owen and Kemp, 2012; Parsons and Lacey, 2012). However, Moffat et al. (2016, p. 484) argue that, for the mining sector at least, "drivers of SLO at the local operational level as well as at national and international scales can be systematically modeled and measured by conducting largescale surveys of citizen attitudes". For example, Zhang et al. (2015) use large-scale surveys 
in Australia, China and Chile to assign quantitative values to key SLO variables such as distributional fairness, procedural fairness, confidence in governance and trust.

Compared to Zhang et al. (2015), Prno and Slocombe (2014) present a more qualitative approach to measuring SLO. They conducted semi-structured interviews with local stakeholders about their perceptions of whether a SLO exists for an Alaskan mine, concluding that "arguably, a relatively strong and long-lasting SLO has been granted for the Red Dog Mine by a majority of individuals in the region" (Prno and Slocombe, 2014, p. 681). Hall (2014) also discusses SLO in terms of "majority" acceptance, while others consider SLO to represent a "consensus" amongst stakeholders (e.g. Thomson and Boutilier, 2011; Moffat et al., 2016). At present, there is no clear consensus in the SLO literature around the thresholds for determining whether a SLO is held for a given activity.

\subsection{SLO variables, criteria and influencing factors}

A number of frameworks for assessing, building and maintaining SLO have emerged from the different industries in which the concept has been applied. Figure 3 summarises the key factors identified as influencing SLO across six such frameworks from the mining, forestry, wind energy and bioenergy industries. The first five were identified as generalised frameworks for determining SLO in a literature review by Baumber (2018), while the sixth framework is the result of Baumber's integration of key factors from the first five frameworks. The authors of the frameworks vary in how they describe the factors shown in Figure 3, using terms such as "variables” (Prno, 2013; Zhang et al., 2015; Baumber, 2018), “criteria" (Thomson \& Boutilier, 2011; Hall, 2014) and "influences" (Dare et al., 2014). The use of "variable" implies a degree of quantitative measurement that is in fact present only in 
the article by Zhang et al. (2015), who surveyed stakeholders on the extent to which they, for example, "Trust the mining industry to act responsibly" Zhang et al. (2015, p. 1067). 


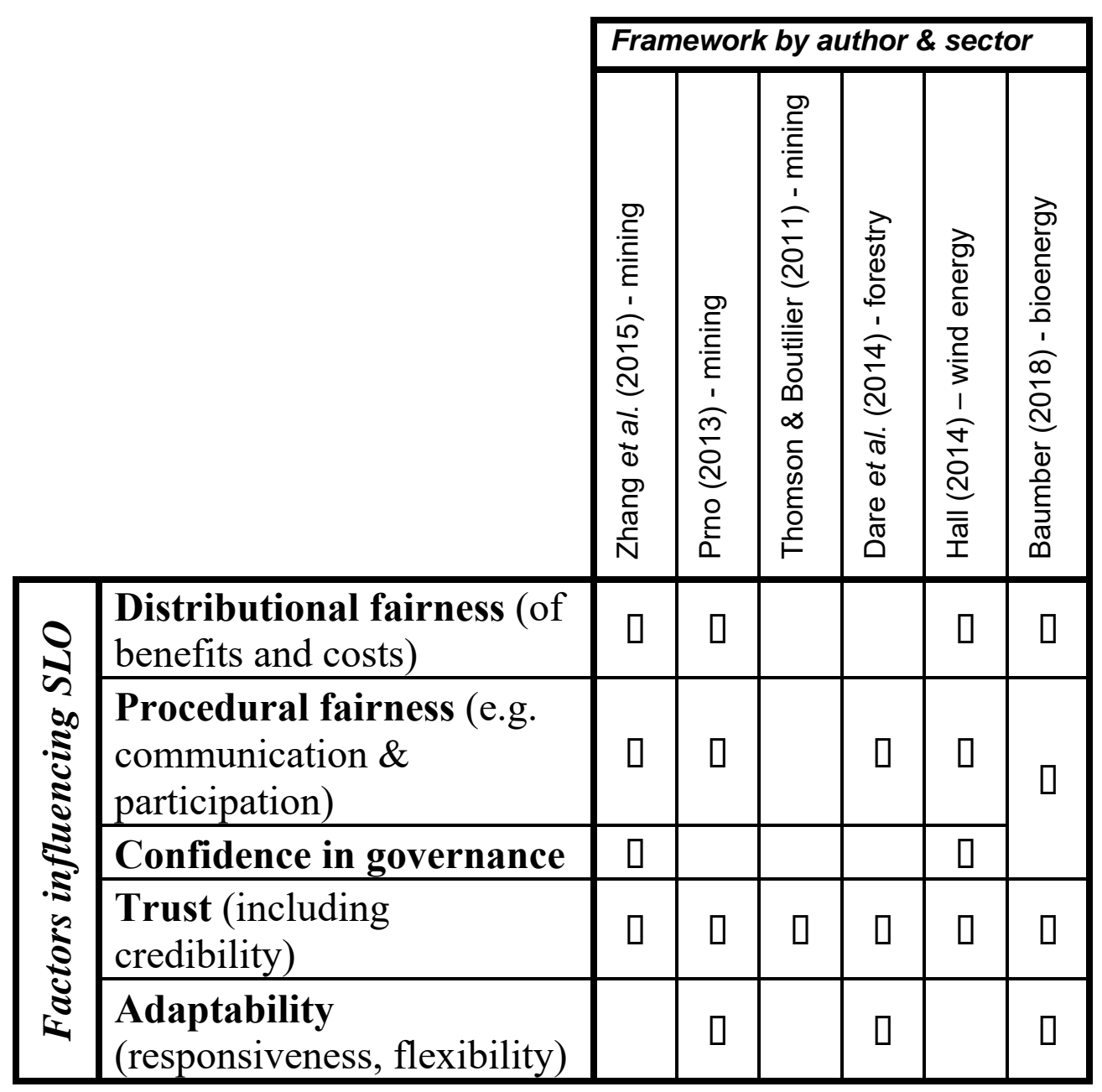

Figure 3: Key influencing factors identified in existing SLO frameworks

Distributional fairness refers to fairness in the outcomes of resource allocation, while procedural fairness refers to perceived justice in the processes of decision-making by those carrying out a particular practice such as mining (Zhang et al., 2015). Baumber (2018) regards confidence in governance as a sub-component of procedural fairness while Zhang et al. (2015) separate it out into its own variable relating to a community's perceptions of whether government regulations covering approval and reporting processes, environmental assessment and public participation are adequate to hold industry to account. 
Adaptability may be classed as a sub-component of other SLO factors, as companies may adapt the way they distribute costs and benefits or the way they conduct decision-making. However, Dare et al. (2014) and Baumber (2018) highlight the value of considering adaptability as a separate factor. For example, business operators may have distributional and procedural strategies that rate highly in terms of fairness at a particular point in time, but are unable to respond quickly to changing community attitudes due to structural inflexibility or poor information flows. Baumber (2018) describes adaptability as encompassing the flexibility, responsiveness and agility of those carrying out a particular practice, while Dare et al. (2014, p. 193) refer to the "ability of organisations to respond to changing expectations".

Trust appears as a key factor in each of the six frameworks in Figure 3 and occupies a central position in the frameworks of Thomson and Boutilier (2011) and Zhang et al. (2015) in particular. In the context of mining, Zhang et al. (2015, p. 1064) define trust as "the extent to which the general public is confident that the mining industry is adhering to a set of accepted principles". They regard distributional fairness, procedural fairness and confidence in governance as factors that each contribute to trust-building. Thomson and Boutilier (2011) consider that once "full trust" is achieved, a community will support and protect an activity as their own, a state they refer to as "psychological co-ownership", the highest possible level of SLO. Thomson and Boutilier (2011) regard credibility as the "foundation of trust" (p. 1785), with credibility built by keeping small promises early on in the community engagement process and responding to disturbances in a manner that shows a commitment to the affected community.

Legitimacy does not appear as a specific factor in Figure 3, but is commonly discussed in SLO frameworks. Dare et al. (2014) equate the granting of a SLO with being "deemed 
legitimate". Similarly, Moffat et al. (2016, p. 479) equate social licence with "legitimacy and social acceptance". Of the six frameworks shown in Figure 3, that of Thomson and Boutilier (2011) is most heavily influenced by prior scholarship into legitimacy. They frame legitimacy as a starting point for SLO, arguing that an entity must first achieve legitimacy before it can achieve credibility and "full trust". Drawing on Knoke (1985) and Suchman (1995), they define legitimacy as public acceptance of a "right to exist" that encompasses pragmatic legitimacy (based on shared interests and concerns), moral legitimacy (based on the following of accepted social norms) and cognitive legitimacy (based on whether a practice "makes sense" to the community). In contrast, Thomson and Boutilier regard credibility to be related to perceptions of honesty and the keeping of promises, and "full trust" to be related to a sense of co-ownership.

While trust is a key factor in SLO, the value of the SLO concept also lies in its capacity to consider factors other than trust. SLO frameworks from the mining, forestry and energy sectors highlight that social licence is about more than just trust and can also be influenced by the distribution of benefits (Hall 2014), perceived fairness of process (Prno, 2013) and a company's responsiveness to changing expectations (Dare et al., 2014). This has parallels in the sharing economy. For example, research into share-bikes in China by Liu and Yang (2018) found that factors relating to user benefits and company processes (usefulness and ease of use) had a more direct impact on behavioural intent than trust, with users prepared to keep using sharebikes even when they "do not believe that providers will keep their promises and commitments and have customers' best interests in mind" (p. 11).

\subsection{SLO states and systems thinking}


Under the framework of Thomson and Boutilier (2011), SLO can exist in a number of different states based on the strength with which it is held. The highest state, "psychological co-ownership", requires a threshold of "full trust" to be passed. This state is described by Thomson and Boutilier (2011) as a dissolution of the "us-them boundary", with the company becoming an insider in the community social network and members of the community actively defending the company against criticisms from outsiders. The notion of multiple potential SLO states also features in the work of Prno and Slocombe (2014) and Baumber (2018), who apply systems thinking to the SLO concept. Systems thinking involves consideration of multiple potential system states with differing degrees of stability and resilience (Walker et al., 2004) and is based on the view that determinist and reductionist approaches are unable to fully explain the processes operating in complex social or ecological systems characterised by pervasive uncertainty, non-linear change, unpredictable disturbances, emergence and self-organisation (Holling et al., 1978; Meadows, 2008).

Prno and Slocombe (2014) combine the idea of SLO states with the systems thinking concept of resilience, with SLO resilience defined as the degree to which "widespread community approval is maintained ... even amid crisis events and other stresses on the companycommunity relationship" (Prno and Slocombe, 2014, p. 679). SLO resilience is represented in Figure 4 using the "basins of attraction" approach to modelling complex systems (Levin et al., 1998; Walker et al., 2004), with each basin representing a different system state (e.g. SLO held or not held). The "ball" may represent an activity or an entity (e.g. proponent or company), as the SLO concept can be applied at the scale of an individual entity such as a mine (e.g. Prno, 2013) or to a broader activity such as mining (e.g. Zhang et al., 2015). A high level of SLO resilience may prevent a social licence being lost when disturbances to the system occur, such as environmental damage, job losses or political influence from outside 
the local community. However, resilience has limits and a social licence may be lost when a combination of low resilience and/or a large disturbance pushes the system past a threshold for change. The ball may also shift into an "altered" state whereby SLO is not lost but key characteristics of the state have changed (e.g. resilience has been lowered or a key threshold has shifted).

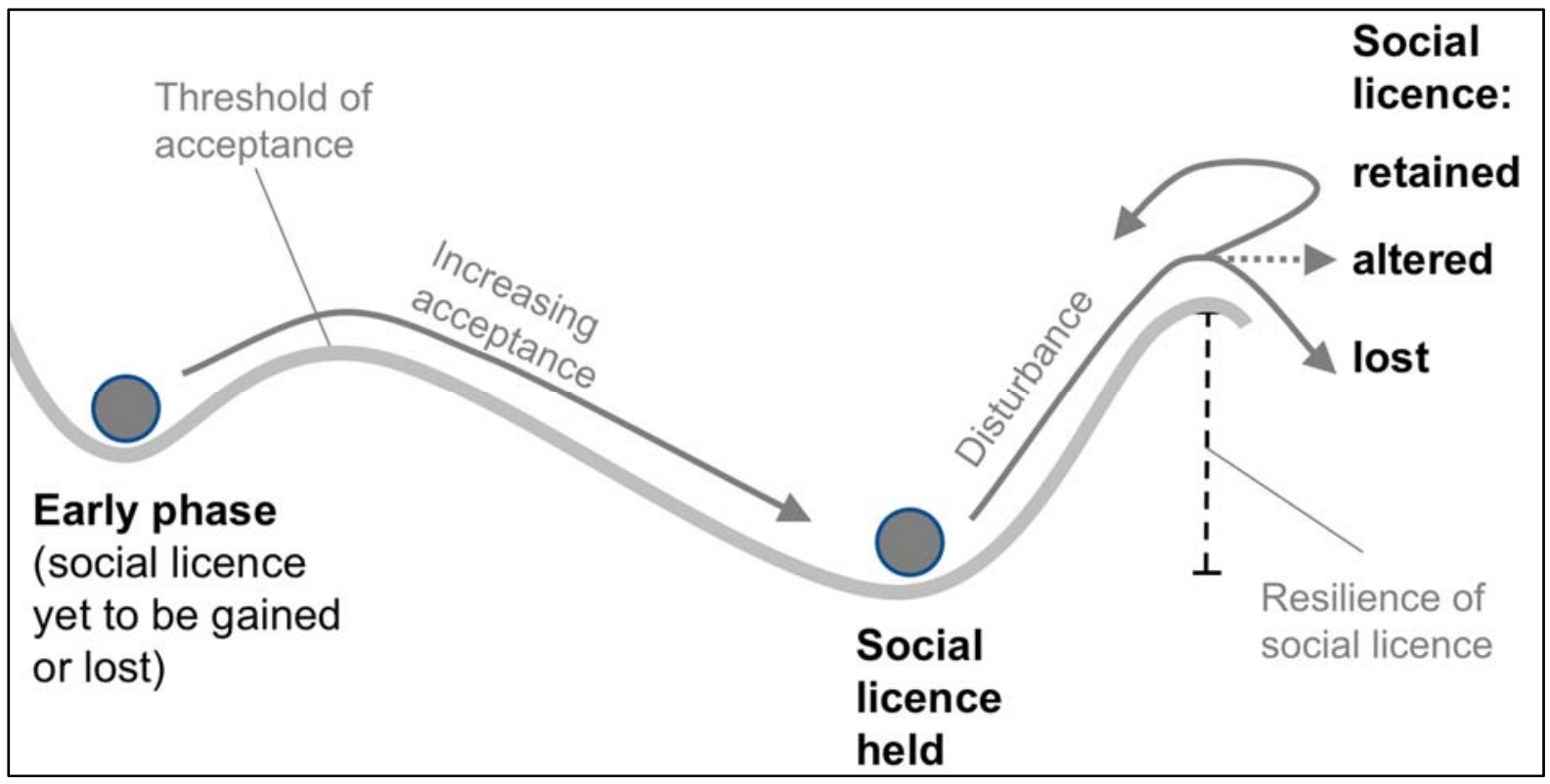

Figure 4: Hypothetical shift in SLO in state for a given activity or entity in a given community. Adapted from Baumber (2018). Note that the ball can move in either direction.

The application of systems thinking concepts such as resilience is still an emerging area of research into SLO. However, it offers the potential to generate new strategies for building SLO and in particular for maintaining it as circumstances change and disturbances to SLO are encountered. A range of general resilience factors that have been shown to enhance resilience in a variety of social, ecological and business contexts (Armitage, 2007; Erol et al., 2010; Carpenter et al., 2012), including: 
- Trust: an element of social capital that can help to overcome social dilemmas such as the incentive to cheat on agreements;

- Diversity: particularly having a diversity of response options that can be drawn on when disturbances arise;

- Reserves and buffers: redundant capacity that can be drawn on in times of need;

- Modularity: the ability to break off parts of an enterprise when needed and to make localised decisions through self-organisation; and

- Monitoring: maintaining good flows of information about the state of the system with short time lags that reduce response times.

The potential interactions between these general resilience factors may have important implications for SLO. For example, while trust has been highlighted as a critical factor in multiple SLO frameworks that have emerged over the past decade, resilience studies highlight that trust is also an important enabler of self-organisation and that reserves of trust built up through repeated interactions can act as a critical buffer when disturbances arise (Carpenter et al., 2012). Thus, understanding SLO resilience may require measurement of not only current trust levels, but also of the size of trust reserves built up through past interactions and the strength of feedbacks between trust and self-organisation.

\section{Developing a SLO framework for the sharing economy}

\subsection{Relevance of the SLO concept to the sharing economy}

Despite the differences in context between the sharing economy and the types of land use activities to which SLO has predominantly been applied to date (e.g. mining, forestry, energy), many of the issues identified in SLO studies have parallels in the sharing economy. Trust, governance and fairness, all factors emphasised in SLO frameworks, have been 
highlighted by Frenken and Schor (2017) as critical considerations for sharing economy activities such as home-sharing and transport. Psychological ownership, which Thomson and Boutilier (2011) consider to be the highest SLO state, has been identified amongst sharing economy stakeholders such as Airbnb hosts (Lee et al. 2019). Community acceptance of sharing economy practices can also be tested by system disturbances, as shown by protests against rising housing costs in Barcelona (Independent, 2017). The link between loss of social licence and tighter government regulation explored in previous SLO research (e.g. Hall 2014) is also apparent in examples such as Sydney's share-bikes and Uber's 2017 loss of its regulatory licence in London (Transport for London, 2017).

While the SLO concept appears broadly applicable to the types of community impacts that are emerging around the sharing economy, a range of factors require further consideration for the development of a specific SLO framework for application to the sharing economy. Sections 5.2 to 5.5 consider contextual differences between extractive industries and the sharing economy, the identification of appropriate communities, the application of the licence metaphor and SLO states to the sharing economy, and the key factors for inclusion in a SLO framework for application to the sharing economy. Section 5.6 proposes our Sharing Economy SLO Framework.

\subsection{Differences in context}

The contexts in which sharing economy platforms have emerged, such as urban transport, short-stay accommodation and task-sourcing, differ considerably from the contexts in which SLO has primarily been considered to date. While sharing economy activities tend to be focused on urban areas where consumers, goods and services are concentrated (Schor, 2016), SLO has mostly been explored outside major cities where mining, forestry and other resource 
use activities occur. For example, in a search of recent academic papers relating to "social licence" (or "social license") through the Web of Science database in July 2018, almost half of the top forty results related to mineral or fossil fuel extraction and almost all related to non-urban activities, including biodiversity conservation, energy conversion, agriculture and fisheries/aquaculture.

Differences in context between rural extractive industries and urban service industries are neither absolute nor insurmountable but may require refinements to the way SLO is applied and conceived of in relation to the sharing economy. Resource extraction, such as coal-seam gas, can affect urban as well as rural communities (Lacey and Lamont, 2014) and sharing economy services can extend to non-urban areas, such as rural homes let through Airbnb. Furthermore, the social licence concept has already begun to cross over from remote extractive industries into highly-urbanised service industries such as banking (O'Brien et al., 2015; Prime Minister of Australia, 2016), horse and greyhound racing (McHugh, 2016; Thomson et al., 2018) and education (Haynes, 2018). Vargo and Lusch (2017) argue that all social and economic actors are in fact "resource integrators", which further removes the distinction between resource extraction and service provision.

Research has begun into social licence in the context of sharing economy practices such as ride-sharing, but currently lacks a clear framework that is informed by experiences with SLO in other sectors. Cohen and Kietzmann (2014) argue that ride-sharing platforms such as Uber could enhance their SLO by collaborating with local governments and seeking to optimise citizen and environmental goals. Stanford (2017, p. 397) implies that at least some digital platform businesses currently hold a social licence, but argues this could be vulnerable if "the impacts of their labour practices become the focus for public attention and concern", 
including avoiding payment of entitlements, evading standards around minimum wages and safety or unfairly passing business risks onto workers or "contractors". This highlights that SLO factors such as distributional fairness and procedural fairness have relevance to the sharing economy, but also raises questions about who should be included in sharing economy communities and how this may differ from notions of community around extractive industries in rural or remote areas.

\subsection{Notions of community}

Many SLO definitions emphasise that the concept is strongly linked to "local" communities. This local dimension was central to the thinking of Jim Cooney when he first applied the term to mining in 1997 (Cooney, 2017) and is highlighted in one of the earliest academic papers on SLO by Joyce and Thomson, who state that SLO "must begin with, and be firmly grounded in, the social acceptance of the resource development by local communities" (Joyce and Thomson, 2000 p. 52). This local dimension has since been re-emphasised in a number of subsequent SLO definitions and frameworks (e.g. Moffat and Zhang, 2014; Prno and Slocombe, 2014; Thomson and Boutilier, 2011).

Some sharing economy platforms may have a local dimension to which SLO can be applied in a similar manner to mining or forestry. For example, certain sharing economy exchanges require physical proximity (e.g. between an Uber driver and a passenger needing a ride) and a common business strategy for activities such as bike-sharing is to locate resources in the densest part of each new city (Cohen and Kietzmann, 2014). In other cases, however, sharing economy platforms may connect service providers and consumers across broad geographic areas, such as tourists connected with holiday accommodation on the other side of the world or services such as web development that can be performed remotely. In such cases, 
membership of an affected community may be determined less by physical proximity to other members of the community than by one's level of engagement with the online platform or the level of impact felt by the exchanges that occur there.

Acquier et al. (2017) argue that, in order to fully understand the community-based dimension of the sharing economy, the term "community" needs to be expanded from its traditional association with strong social ties operating at the local level to recognise communities of more weakly connected individuals with shared experiences and interests. People who use online platforms to offer or purchase services are the most obvious members of a sharing economy community (i.e. a community of users). A range of other actors within the service "ecosystem" may also qualify as community members, including the owners and employees of the platform, the media and policy-makers (Breidbach and Brodie, 2017), as well as those who are part of sub-economies or secondary markets that support major platforms (Sigala, 2017). However, the extent to which any of these actors self-identify as community members may depend on a variety of factors, such as their level of interaction, their loyalty to a particular platform and whether they view their involvement as transactional or part of a collective social mission (Acquier et al., 2017).

Apart from those who are directly connected to a sharing economy platform, the affected community may also include a range of people who are indirectly affected by the exchanges that take place. These indirect impacts include those felt by the local urban communities highlighted in the introduction to this article, including renters affected by increased housing costs (e.g. due to short-letting services such as Airbnb), commuters with an interest in the cost, reliability and safety of transport options (including ride-sharing services such as Uber), workers affected by an erosion of labour standards (e.g. due to task-sourcing services such as 
Airtasker) or residents affected by the negative aesthetics of share bikes left in inappropriate locations.

The potential for internet-based platforms to create sharing economy communities that are widely dispersed and weakly linked may at first appear to preclude the use of a concept like SLO, which is rooted in direct impacts on local communities. However, SLO researchers have over time expanded the concept by applying it to affected communities defined at different scales or in a non-spatial manner. For example, Zhang et al. (2015) examine the social licence of mining industries at the national rather than local scale and Ford and Williams (2016) argue for SLO to consider both communities of place (delineated by location) and communities of interest (delineated by shared values). Dare et al. (2014) also consider communities of both place and interest and argue that SLO should be conceived of as multiple overlapping licences negotiated with these different communities.

Aside from the questions it raises around defining "local" communities, the sharing economy also has a tendency to blur "the conventional boundary between the economy and everyday life" (World Economic Forum, 2016), including the boundary between community members and consumers. This has implications for the application of SLO, which Ford and Williams (2016) argue is typically focused on relationships between companies and local communities rather than on relationships with consumers. When SLO is applied to the mining sector, the focus is generally on people who live near mines (and may even work in them), but not usually on the people who buy or sell the outputs of mining (e.g. Moffat and Zhang, 2014; Prno and Slocombe, 2014). In contrast, for sharing economy platforms it is arguable that the community members most directly affected by a platform are those who use it to exchange goods and services. 
Applying the SLO concept to the sharing economy may require a more expansive conceptualisation of community that not only goes beyond the local scale but also includes users and customers as community members. There are precedents for this in the academic literature, with O'Brien et al. (2015) explicitly considering bank customers as affected stakeholders when applying SLO to the finance sector and Haynes (2018) including students as affected stakeholders in relation to the SLO of education. However, it is crucial that any sharing economy SLO framework goes beyond consumer or market acceptance to consider other affected stakeholders. Drawing on the framework of Wüstenhagen et al. (2007), in which social acceptance is divided into "community", "market" and "socio-political" acceptance, it is arguable that SLO in the sharing economy has a stronger overlap between the community and market dimensions than is typical for SLO examples in the mining, forestry or energy sectors.

\subsection{The licence metaphor and system states}

The emergence of the social licence metaphor within the mining, forestry and energy sectors is unsurprising given the widespread requirement for regulatory approvals to be obtained before such activities may commence. In these contexts, a social licence is often framed as something that is additional to a regulatory licence (Hall, 2014; Morrison, 2014) and failure to obtain a social licence may result in a loss of regulatory approval (Franks et al., 2011; Hall et al., 2013). However, for many sharing economy activities (e.g. gig work, home-sharing), a regulatory licence may not be required and in other cases, operations may commence despite being illegal, such as with ride-sharing in Japan, Taiwan and Saudi Arabia (Watanabe et al., 2017). Affected stakeholders have pressured governments in some instances to impose greater regulations on emerging platforms, such as has been observed in Australia around 
Airtasker (The Senate Education and Employment References Committee, 2017;

UnionsNSW, 2016) and dockless bike-share schemes (ABC News, 2018). However, in other cases, a groundswell of community support may lead to the creation of legal opportunities for previously illegal activities, such as in Singapore, where the government's legalisation of Uber's operations was at least partly a response to a finding that "young people enjoy using services like Uber" (Watanabe et al., 2017 p. 40).

Where sharing economy practices commence in an unregulated manner, there is an opportunity to frame SLO as an alternative to a regulatory licence rather than something that complements it, with the potential to avoid unfavourable new regulations providing an incentive for sharing economy platforms to obtain a social licence. There is also scope to consider the SLO of entire industries or practices rather than specific businesses. This has already been done for SLO around mining and forestry (Zhang et al., 2015; Edwards and Trafford, 2016) and sharing economy SLO has the potential to be evaluated at the scale of a single company (e.g. Uber) or at the scale of practice or industry (e.g. ride-sharing more broadly). This presents an opportunity for cross-platform collaboration to obtain a social licence around emerging practices that heads off the introduction of unfavourable regulation.

The complex relationships between social licence and regulatory licence in the sharing economy have implications for the notion of SLO "states". In Figure 4, an "early" system state was identified in which social licence was yet to be decided upon. This is likely to occur when a platform or activity is new and small-scale and has not yet attracted the attention of regulators or potentially-affected communities (Demailly, 2014). It is difficult for mining activities to go "under the radar" in the same way due to regulatory requirements for development approval that commonly require a degree of community consultation (Thomson 
and Boutilier, 2011). As such, a crucial component of any sharing economy SLO framework is the degree of visibility around a platform's activities and the amount of information that stakeholders have available to make decisions around SLO.

\subsection{SLO factors, criteria and variables}

A key question for the application of SLO to the sharing economy is whether the same factors that have been applied to SLO in mining and other sectors (e.g. trust, distributional fairness, procedural fairness, governance and adaptability) are also relevant in sharing economy contexts. There are clear examples where concerns have arisen around each of these factors in relation to the sharing economy. For example, returning to the four sharing economy examples cited in the introduction to this article (Airbnb, Uber, Airtasker and sharebikes), the following factors can be observed:

- Trust: Community concerns have been raised in Australia about how bike-share companies use and sell user data (ABC News, 2017). Similarly, a lack of trust has been identified as a potential obstacle to the growth and long-term viability of sharebike companies in China (Liu and Yang, 2018).

- Distributional fairness: Gutiérrez et al. (2017) argue that the costs of increased tourism in Barcelona, including from Airbnb, have been disproportionately borne by local residents in the city centre. These include rising housing costs and overcrowding, with protesters targeted the perceived unfairness of these impacts in 2017.

- Procedural fairness: The fairness and transparency of Uber's surge pricing mechanism has been questioned by researchers and local stakeholders (Chen et al., 2015). In particular, the "opaqueness" of the surge pricing mechanism was cited by 
Chen et al. (2015) as a factor that decreased community confidence in the fairness of Uber's processes.

- Confidence in governance: A failure of governments to maintain appropriate regulations covering newly-emerging contractual arrangements (or lack thereof) for gig economy workers (e.g. Uber and Airtasker) has been cited as a concern in the US, Canada and Australia (Stanford, 2017). The Senate Education and Employment References Committee (2017) in Australia highlighted this perceived lack of confidence in governance by stating that "to its critics, the gig economy is dangerously unregulated and creates fertile ground for exploitation” (p. 85).

- Adaptability: Airtasker provides an example of responsiveness to changing expectations, specifically around the pay rates they recommend for specific tasks. In 2017, Airtasker responded to union criticism in Australia by making a deal on pay rates with local unions (The Senate Education and Employment References Committee 2017). UnionsNSW secretary Mark Morey responded that "others should follow Airtasker's example and consider the ethical dimension of their impact" (SMH, 2018), highlighting the potential for social licence to be enhanced or maintained through quick responses to emerging controversies.

While each of the factors above have relevance to SLO in the sharing economy, it is not yet known which of these are most important in the sharing economy or whether other factors should be included in a sharing economy SLO framework. Furthermore, if SLO is conceived of as multiple overlapping licences negotiated with different stakeholder groups (Dare et al., 2014), it is possible that some factors may be more relevant for some groups than others. For example, building trust is a critical consideration for emerging sharing economy platforms, especially as users need to trust one another as well as the platform as an intermediary and 
cannot always rely on government regulations to protect them (Penz et al., 2018). However, discussions of trust around the sharing economy typically focus on interactions between platforms and users, or "consumer communities" (Penz et al., 2018). A key unknown is the extent to which trust created within these consumer communities impacts on the level of trust amongst non-users who may be affected by a platform's activities.

A final consideration before presenting our Sharing Economy SLO Framework is the extent to which the different SLO factors influence the initial obtaining of a SLO, relative to the ongoing maintenance of one. This requires a consideration of resilience factors within the framework. Baumber (2018) argues that adaptability and trust are the SLO factors most relevant to SLO maintenance and resilience. Several of the "general resilience" factors highlighted by Carpenter et al. (2012) enhance adaptability, including response diversity (having a range of options available in a crisis), modularity/self-organisation (independence within different parts of an operation) and monitoring (enabling rapid responses to changing circumstances). Also, as highlighted by Carpenter et al. (2012), trust is a general resilience factor in itself (enabling system actors to overcome incentives to cheat one another), as well as having important interactions with other general resilience factors such as buffering (reserves of trust can be built up or denuded over time) and modularity (trust is an important enabler of self-organisation).

\subsection{Sharing Economy SLO Framework}

Figure 5 combines the various factors discussed in sections 5.1 to 5.5 into an overarching framework for understanding SLO in relation to the sharing economy that can be applied by a variety of stakeholders, including sharing economy platforms, industry bodies, government 
and researchers. It is designed to be an adaptive framework that can be refined further through future research rather than a final product.

The main body of the framework (i.e. the left-hand side) focuses on how SLO is gained, maintained or lost within a discrete community (e.g. of users, interest or place). It employs the analogy of a ball in a basin from Figure 4 to highlight that activities may exist in different SLO states separated by thresholds (note that the size and shape of the basins in Figure 4 are for illustrative purposes only and may vary in practice). Some factors may play a greater role in whether SLO is obtained initially, while others may play a greater role in whether it is maintained over the longer-term. The factors at the top of the list (distributional fairness, procedural fairness, governance and trust) have been identified in past SLO frameworks as influencing whether a SLO is likely to be obtained (Zhang et al., 2015; Hall, 2014; Dare et al., 2014). The factors towards the bottom (monitoring, response diversity, modularity and reserves/buffers) have been shown to enhance resilience across a range of socio-ecological systems (Armitage, 2007; Erol et al., 2010; Carpenter et al., 2012) and are thus most relevant where an established SLO is subject to potential disturbances. Adaptability, cited as a key SLO factor by Baumber (2018), has not been included as a specific factor in Figure 4, but is instead represented by the factors that influence it, such as response diversity, monitoring and modularity.

The framework's focus on both obtaining and maintaining a SLO represents a key point of difference with existing SLO frameworks such as those presented by Zhang et al. (2015) and Hall (2014), which do not differentiate between the factors involved in obtaining versus maintaining SLO. This is particularly relevant to the sharing economy, given the complex relationships between social licence and regulatory approval and the differing levels of 
visibility that sharing economy practices may have amongst different stakeholder groups. However, this aspect of the framework is also subject to much uncertainty, with the full list of factors and the level of influence that each has on gaining or maintaining a SLO to be refined through further research.

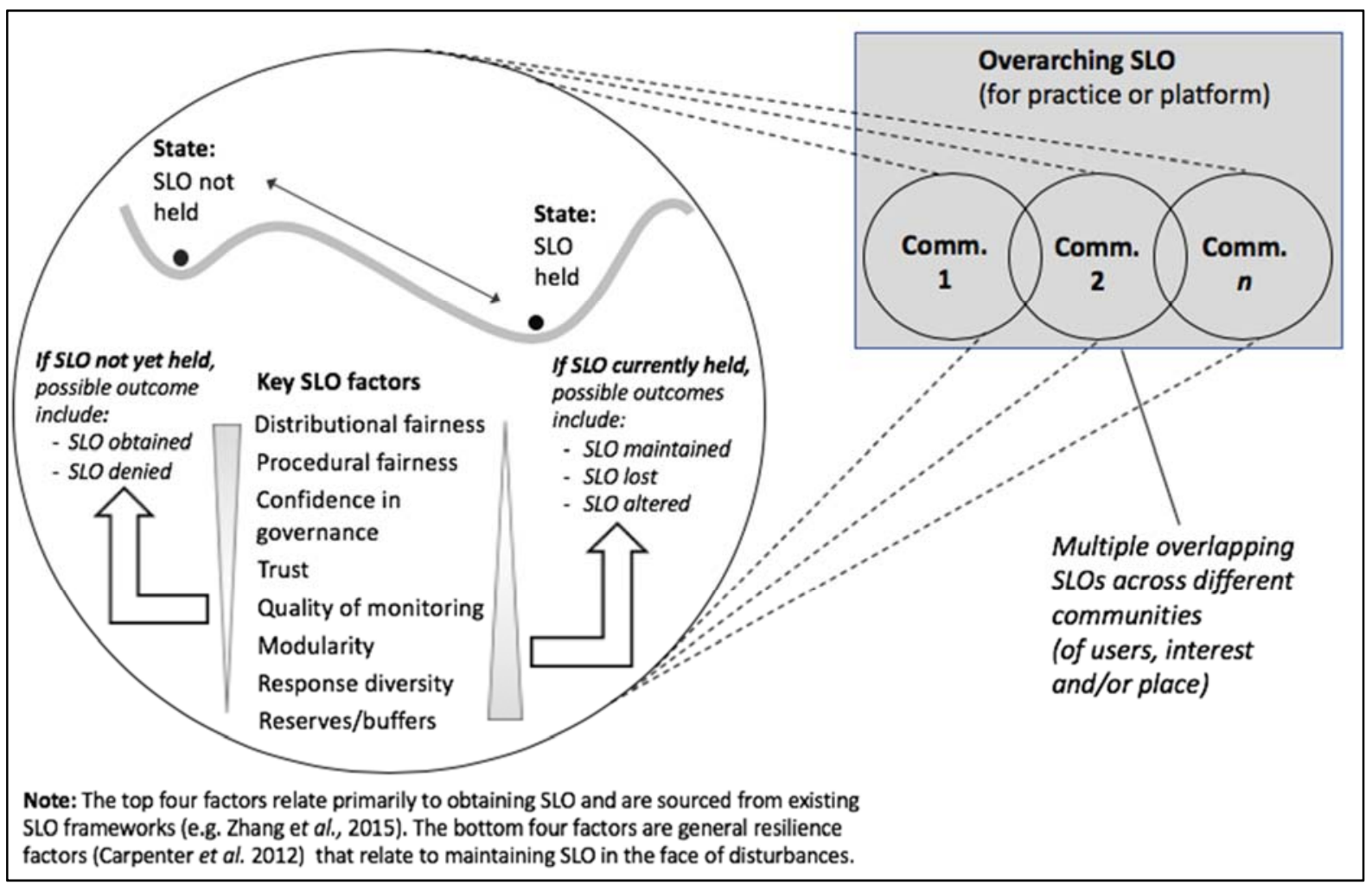

\section{Figure 5: Sharing Economy SLO Framework}

To provide an example of how the model might operate in practice, one might imagine a new sharing economy activity that emerges in a city. This activity would initially reside in the left-hand basin of the ball-in-basin model ("SLO not held"). Following scholars such as Zhang et al. (2015), the model indicates that higher levels of distributional fairness, procedural fairness, confidence in governance and trust would increase the chances of the activity shifting into the "SLO held" state. However, once a practice resides in the "SLO 
held" state, the ongoing maintenance of this SLO may be threatened by unpredictable disturbances. The model suggests that, in these circumstances, general resilience factors such as monitoring quality, modularity, response diversity and the size of reserves/buffers are likely to play a greater role than they would in the initial obtaining of a SLO. For example, a business' response time following a disturbance may be reduced by effective monitoring of trust levels amongst key stakeholders and having a diversity of response options available (e.g. new algorithms for matching suppliers to consumers or alternative business models that extract revenue from different points in the supply chain). Modularity may enable business units that have lost trust to be shed and perceptions of fairness may be enhanced by allowing users of a sharing platform to self-organise by setting their own prices or rules. Reserves of goodwill, built up through repeated trustful interactions, may enable the sharing economy activity to "ride out" controversies for a longer period of time.

In the top right of the framework in Figure 5, SLO is represented as a series of overlapping licences held with different communities. This draws on the work of Dare et al. (2014) and Ford and Williams (2016) on SLO, as well as that of Acquier et al. (2017) on the nature of sharing economy communities. The framework indicates that multiple community-scale SLOs may combine to form a larger broad-based SLO covering multiple communities. An overarching SLO may cover a single sharing economy platform that affects a number of different communities (e.g. communities of users, interest or place). Alternatively, an overarching SLO may cover a broader practice such as ride-sharing, where the work of multiple businesses in gaining community-scale SLOs may combine to form a broader overarching SLO for the practice in question.

\section{Research agenda for SLO and the sharing economy}


To operationalise and adapt the sharing economy SLO framework presented in section 5.6, a number of research questions need to be answered through targeted case studies on the sharing economy in different contexts. This includes research into the key stakeholders involved in determining SLO in the sharing economy (section 6.1), the potential benefits and risks of applying SLO to the sharing economy (6.2), identifying key SLO factors and measurable SLO variables (6.3) and developing strategies for building and maintaining SLO (6.4).

\subsection{Stakeholder analysis}

Sharing economy communities are made up of a diversity of stakeholders, including platforms operators, users (including providers and consumers), supporting service providers (e.g. secondary markets that support major platforms; Sigala, 2017), disrupted stakeholders (e.g. taxi drivers disrupted by Uber), regulators and local stakeholders affected by activities such as home-sharing or bike-sharing. Understanding SLO for each of these stakeholder groups and the role that each group plays in determining an "overarching" SLO requires social research to identify the different stakeholder groups, understand their relationships with sharing economy platforms and practices and assess the inter-relationships between these different groups.

Stakeholder analysis into the sharing economy has already been undertaken by a variety of researchers, offering a number of tools and frameworks that could be used to operationalise the Sharing Economy SLO Framework. Dreyer et al. (2017) used onsite observations and semi-structured interviews to inform their multi-stakeholder value mapping of sharing economy practices in South Africa. Breidbach and Brodie (2017) present a "service ecosystem" framework for identifying how different actors engage with sharing economy 
practices. Acquier et al. (2017) highlight that sharing economy platforms have the potential to re-shape what we commonly think of a community, requiring us to consider weaklyconnected individuals linked by digital online platforms. Stakeholder analysis of this nature may also shed further light on what constitutes the "community-based" dimension of the sharing economy, with SLO potentially offering a means of defining community-based through community acceptance and shared interests (Dare et al., 2014), rather than whether practices are non-hierarchical or non-monetized (Acquier et al., 2017).

Given that the SLO concept is not primarily focused on consumer relations (Ford and Williams, 2016), any stakeholder analysis into sharing economy SLO needs to go beyond platform users, where much stakeholder analysis has focused to date (e.g. Dreyer et al. 2017; Liu and Yang 2018; Penz et al. 2018), However, it is also important not to exclude platform users, as they are key component of the new communities being formed around sharing economy practices (Acquier et al., 2017). Furthermore, there is a high degree of overlap amongst sharing economy communities, whereby individual stakeholders may simultaneously be providers of goods or services, as well as consumers, members of disrupted industries (e.g. taxi drivers who also drive for Uber) and local residents affected by changing practices.

\subsection{Potential benefits and risks of applying SLO to the sharing economy}

Stakeholder perspectives are likely to vary by stakeholder type, the nature of the practices involved and whether they are profit-driven or based on a community-based ethic. For platform operators, SLO may have the potential to act as an "early warning" system to help avoid losing an existing regulatory approval, having new regulations imposed on them or encountering additional costs associated with community conflict. Managing political, 
financial and reputational risks was a key motivation for the introduction of SLO in mining (Cooney, 2017) and the negative consequences of failing to obtain a SLO have been observed across a range of land use activities (Franks et al., 2014; Hall et al., 2013). The examples of Uber, Airbnb, Airtasker and dockless bike-share schemes that opened this article demonstrate that such risks are also present in relation to the sharing economy.

Using SLO as an early warning system could also have benefits for governments, in terms of knowing when regulation is required and when to step back from regulation. Key research questions around this include how social licence and regulatory licence interact around the sharing economy and how SLO could be measured effectively. As discussed in section 5.4, the relationships between SLO and regulatory licensing are likely to be different in the sharing economy than in extractive industries, with further case study research required to better understand these relationships. SLO measurement is considered in the following section.

The application of the Sharing Economy SLO Framework may also enable strategies to be developed for gaining and maintaining SLO (discussed further in section 6.5). This could have a clear benefit for platforms, as well as for government agencies wishing to guide emerging platforms and avoid potential conflict. For other affected stakeholders, this may result in greater consideration being given to the benefits and costs they face and opportunities to have a greater say in how sharing economy platforms develop, due to the SLO focus on distributional and procedural fairness. However, there is also a risk that the SLO concept could be co-opted by platforms looking for endorsement of their practices by researchers or government. Advocates of community-based sharing practices may see a benefit in recognising SLO and developing strategies to build it for practices they support, 
but not for profit-driven practices that clash with their values (Martin, 2016). Attempts to reframe SLO as a more permanent endorsement that provides security for ongoing operations have been observed in the mining sector and resisted by SLO researchers (Thomson and Boutilier, 2011).

\subsection{Identifying key SLO factors and measurable variables}

The Sharing Economy SLO Framework recognises factors identified in previous SLO frameworks (distributional fairness, procedural fairness, governance, trust and adaptability), but also expands these by adding factors from resilience studies, including buffering, response diversity, modularity and monitoring. SLO methodologies developed in mining and other sectors offer a starting point for measuring these factors in the sharing economy and potentially identifying new factors to add to the framework. These measurement approaches could include large-scale citizen surveys to quantify key variables (e.g. Zhang et al., 2015), as well as qualitative approaches using semi-structured interviews with key informants (e.g. Prno and Slocombe, 2014). Enterprise resilience studies offer a means of integrating resilience factors into these existing methods (Erol et al., 2010).

Aside from existing SLO methodologies, the sharing economy presents opportunities to utilise different data sources to those commonly available in sectors such as mining, including media reporting on the sharing economy, sentiment analysis using social media and online forums, and utilising the vast amounts of data captured by sharing economy platforms themselves (e.g. user ratings and feedback). For example, Chang and Wang (2018) undertook sentiment analysis on online reviews from Airbnb and Home-Away to better understand how such reviews help to build trust in sharing economy platforms. Future case study analysis in the sharing economy could analyse how such data sources provide indicators for other SLO 
factors, such as distributional fairness, procedural fairness, governance and information flows, and may help to identify whether additional factors need to be added to the framework.

Drawing on systems thinking approaches to SLO (Prno and Slocombe 2014; Baumber 2018), the Sharing Economy SLO Framework also incorporates the concepts of non-linear change and thresholds for shifting between system states. As such, a key focus for measuring SLO variables is the identification of thresholds beyond which SLO may be gained or lost. This could include case study analysis of emerging platforms that gained or failed to gain a SLO and existing platforms that have lost their SLO. The most contentious threshold of all is likely to be the threshold of community acceptance beyond which a SLO can be said to be held. While SLO in the mining, forestry and energy sectors has sometimes been defined in terms of "majority" acceptance (e.g. Hall, 2014; Prno and Slocombe, 2014), others consider it to represent a "consensus" amongst stakeholders (e.g. Thomson and Boutilier, 2011; Moffat et al., 2016). Determining such thresholds for the sharing economy is likely to require multistakeholder discourse based around case study analysis and identification and measurement of appropriate variables.

\subsection{Strategies for obtaining and maintaining SLO}

Analysis of previous SLO studies may offer practical assistance for building social licence in the sharing economy, including strategies around high-quality contact with stakeholders to enhance procedural fairness (Moffat and Zhang 2014) and building trust by keeping small promises early and responding in the community's interest when disturbances occur (Thomson and Boutilier, 2011). While trust-building strategies for the sharing economy have been explored by Penz et al. (2018), the Sharing Economy SLO Framework presents an opportunity to expand this research beyond "consumer communities" into other communities 
affected by sharing economy practices. Aside from SLO-specific studies, there is also the potential to incorporate legitimacy frameworks developed for new entrants in business settings more broadly into SLO strategies (Drori and Honig, 2013; Laïfi and Josserand, 2016).

Future research questions around building and maintaining social licence in the sharing economy include how SLO strategies could be refined to incorporate factors that have been argued to enhance the "community-based" dimension of the sharing economy, such as shared social mission (Acquier et al. 2017), peer-to-peer exchange (Habibi et al., 2016) and sustainability objectives (Heinrichs, 2013). However, the roles of these factors in building SLO are uncertain and perverse outcomes are possible that can counteract the goals of platform developers, such as greater use of underutilised resources giving way to overconsumption (Parguel et al., 2017). As such, hypotheses could be developed to test each of these factors using the measurement methods outlined previously. These results could in turn help to inform future strategies for building and maintaining SLO in the sharing economy.

\section{Conclusion}

While the sharing economy has grown to become a core component of many regional and national economies, it remains an evolving economic sector with a high level of heterogeneity and loosely defined boundaries. Alongside the many benefits that the sharing economy can bring are emerging negative impacts for some members of the communities affected by the formation of new service practices and relationships. Other sectors such as mining and forestry have also had to contend with negative impacts of new activities and, as 
such, provide a potential source of both conceptual frameworks and practical knowledge that may shed light on the "dark side" of the sharing economy.

In this article, we have demonstrated the applicability of the SLO concept to the sharing economy by analysing how SLO has been applied in other sectors, exploring recent examples of community conflict around the sharing economy, and proposing a Sharing Economy SLO Framework that can inform future research. While the purpose of this paper was not to produce detailed case study analysis of SLO in the sharing economy, we have identified opportunities where case study research could help to refine existing knowledge about both the sharing economy and the SLO concept.

This article has highlighted similarities as well as important differences between the sharing economy and sectors such as mining where SLO has been applied previously. In particular, the overlap between market acceptance and community acceptance may be greater in relation to the sharing economy and defining "community" may require a greater consideration of non-spatial factors such as online interactions and shared interests. The key factors determining SLO and the relationships between these factors may also differ from SLO frameworks developed in the mining, forestry and energy sectors. The central role of the internet and other information and communication technologies in the sharing economy also raises important questions around the meaning of "local" and creates opportunities to use new data sources in the measurement of SLO.

The SLO concept may require adaptation for use in the sharing economy context and SLO is not the only way to shed light on the "dark side" of the sharing economy. However, the knowledge gained from the application of SLO to multiple industries with a history of 
managing contentious impacts over the past two decades represents a valuable base on which to build. Through the bringing together of social licence and the sharing economy, opportunities exist for mutual learning to simultaneously enhance our understanding of the sharing economy and refine the SLO concept by conceiving of "community" in new ways, identifying factors that affect SLO in different contexts and developing new approaches to measure, build and maintain social licence.

\section{References}

ABC News, 2017. "Bike share schemes may seem a waste of space but the economics makes sense". http://www.abc.net.au/news/2017-09-19/bike-share-schemes-economicsmakes-sense-the-conversation/8957404. Accessed: 23 March 2018, Updated: 19 September 2017

ABC News, 2018. "Waverley Council loses patience with bike share trash in Sydney's eastern suburbs". http://www.abc.net.au/news/2018-03-05/waverley-council-losespatience-with-bike-share-trash/9509838. Accessed: 6 March 2018, Updated: 5 March 2018

Acquier, A., Daudigeos, T., Pinkse, J., 2017. Promises and paradoxes of the sharing economy: An organizing framework. Technological Forecasting and Social Change. 125, 1-10.

Armitage, D. 2007. Building Resilient Livelihoods through Adaptive Co-Management: The Role of Adaptive Capacity. In: Armitage, D., Berkes, F. and Doubleday, N. (eds.) Adaptive Co-Management. Vancouver: UBC Press, 62-82. 
Barnes, S.J., Mattsson, J., 2016. Understanding current and future issues in collaborative consumption: A four-stage Delphi study. Technological Forecasting \& Social Change. 104, 201-211.

Baumber, A., 2018. Social licence and energy cropping: What's trust got to do with it? Biomass \& Bioenergy. 108, 25-34.

Belk, R., 2014. You are what you can access: Sharing and collaborative consumption online. Journal of Business Research. 67, 1595-1600.

Botsman, R., Rogers, R., 2010. What's Mine is Yours: How Collaborative Consumption is Changing the Way We Live. Collins, London.

Breidbach, C.F., Brodie, R.J., 2017. Engagement platforms in the sharing economy. Journal of Service Theory and Practice. 27, 761-777.

Bucher, E., Fieseler, C., Lutz, C., 2016. What's mine is yours (for a nominal fee) e Exploring the spectrum of utilitarian to altruistic motives for Internet-mediated sharing. Computers in Human Behavior. 62, 316-326.

Cannon, S., Summers, L.H., 2014. How Uber and the sharing economy can win over regulators. Harvard Business Review. 10, 1-4.

Carpenter, S.R., Arrow, K., Barrett, S., Biggs, R., Brock, W., Crépin, A.-S., Engström, G., Folke, C., Hughes, T.P., Kautsky, N., Li, C.-Z., McCarney, G., Meng, K., Mäler, K.-G., Polasky, S., Scheffer, M., Shogren, J., Sterner, T., Vincent, J., Walker, B., Xepapadeas, A., de Zeeuw, A., 2012. General Resilience to Cope with Extreme Events. Sustainability 4, 1-12.

Chang, W.-L., and Wang, J.-Y. (2018). Mine is yours? Using sentiment analysis to explore the degree of risk in the sharing economy. Electronic Commerce Research and Applications. 28, 141-158. 
Chen, L., Mislove, A., and Wilson, C. (2015). Peeking Beneath the Hood of Uber. Proceedings of the 2015 Internet Measurement Conference. City: ACM: Tokyo, Japan, pp. 495-508.

Cohen, B., Kietzmann, J., 2014. Ride On! Mobility Business Models for the Sharing Economy. Organization \& Environment. 27, 279-296.

Cooney, J., 2017. Reflections on the 20th anniversary of the term 'social licence'. Journal of Energy \& Natural Resources Law. 35, 197-200.

Cusumano, M.A., 2015. How traditional firms must compete in the sharing economy. Communications of the ACM. 581, 32-34.

Dare, M., Schirmer, J., Vanclay, F., 2014. Community engagement and social licence to operate. Impact Assessment and Project Appraisal. 32, 188-197.

Demailly, D., Novel, A., 2014. The sharing economy: make it sustainable, IDDRI (Institut du développement durable et des relations internationales), Paris.

Dreyer, B., Lüdeke-Freund, F., Hamann, R., and Faccer, K. (2017). Upsides and downsides of the sharing economy: Collaborative consumption business models' stakeholder value impacts and their relationship to context. Technological Forecasting and Social Change. 125, 87-104.

Edwards, P., Lacey, J., Wyatt, S., Williams, K.J.H., 2016. Social licence to operate and forestry - an introduction. Forestry. 89, 473-476.

Edwards, P., Trafford, S., 2016. Social licence in New Zealand-what is it? Journal of the Royal Society of New Zealand. 46, 165-180.

Erol, O., Sauser, B.J., Mansouri, M., 2010. A framework for investigation into extended enterprise resilience. Enterprise Information Systems. 4, 111-136. 
Ford, R.M., Williams, K.J.H., 2016. How can social acceptability research in Australian forests inform social licence to operate? Forestry. 89, 512-524.

Franks, D., Boger, D., Cote, C., Mulligan, D., 2011. Sustainable development principles for the disposal of mining and processing wastes. Resource Policy. 36, 114-122.

Franks, D.M., Davis, R., Bebbington, A.J., Ali, S.H., Kemp, D., Scurrah, M., 2014. Conflict translates environmental and social risk into business costs. Proceedings of the National Academy of Sciences of the United States of America. 111, 7576-7581.

Frenken, K., Schor, J., 2017. Putting the sharing economy into perspective. Environmental Innovation and Societal Transitions. 23, 3-10.

Gutiérrez, J., García-Palomares, J. C., Romanillos, G., and Salas-Olmedo, M. H. (2017). The eruption of Airbnb in tourist cities: Comparing spatial patterns of hotels and peerto-peer accommodation in Barcelona. Tourism Management. 62, 278-291.

Habibi, M. R., Kim, A., and Laroche, M. (2016). From Sharing to Exchange: An Extended Framework of Dual Modes of Collaborative Nonownership Consumption. Journal of the Association for Consumer Research. 1(2), 277-294.

Hall, N., Ashworth, P., Devine-Wright, P., 2013. Societal acceptance of wind farms: Analysis of four common themes across Australian case studies. Energy Policy. 58, 200208.

Hall, N.L., 2014. Can the "Social Licence to Operate" Concept Enhance Engagement and Increase Acceptance of Renewable Energy? A Case Study of Wind Farms in Australia. Social Epistemology. 28, 219-238.

Hall, N., Lacey, J., Carr-Cornish, S., and Dowd, A.-M. (2015). Social licence to operate: understanding how a concept has been translated into practice in energy industries. Journal of Cleaner Production, 86, 301-310. 
Hamari, J., Sjoklint, M., Ukkonen, A., 2015. The sharing economy: why people participate in collaborative consumption. Journal of the Association for Information Science and Technology. 67, 2047-2059.

Haynes, B., 2018. The role of trust in the teaching of history. Educational Philosophy and Theory. 50, 174-182.

Heinrichs, H., 2013. Sharing economy: a potential pathway to sustainability. GAIA. 22, 228231.

Holling, C.S., Bazykin, A., Bunnell, P., Clark, W.C., Gallopin, G.C., Gross, J., Hilborn, R., Jones, D.D., Peterman, R.M., Rabinovich, J.E., Steele, J.H., Walters, C.J., 1978. Adaptive Environmental Assessment and Management, Reprint of 1978 edition ed. The Blackburn Press, Caldwell, New Jersey, USA.

Independent, 2017. "Why Barcelona Locals Really Hate Tourists". http://www.independent.co.uk/travel/news-and-advice/barcelona-locals-hatetourists-why-reasons-spain-protests-arran-airbnb-locals-attacks-graffitia7883021.html. Accessed: 18 February 2018, Updated: 9 August 2017

Joyce, S., Thomson, I., 2000. Earning a social licence to operate: social acceptability and resource development in Latin America. Canadian Mining and Metallurgical Bulletin. 93, 49-53.

Knoke, 1985. "The political economies of associations”. In: Braungart, R. G. \& Braungart, M. M. (Eds) Research in Political Sociology Vol. 1 (pp. 211-242). Greenwich, CT: JAI press.

Lacey, J., Lamont, J., 2014. Using social contract to inform social licence to operate: an application in the Australian coal seam gas industry. Journal of Cleaner Production. 84, 831-839. 
Lee, H., Yang, S.-B., and Koo, C. (2019). Exploring the effect of Airbnb hosts' attachment and psychological ownership in the sharing economy. Tourism Management. 70, 284-294.

Levin, S.A., Barrett, S., Aniyar, S., Baumol, W., Bliss, C., Bolin, B., Dasgupta, P., Ehrlich, P., Folke, C., Gren, I.-M., Holling, C.S., Jansson, A., Jansson, B.-O., Maler, K.-G., Martin, D., Perrings, C., Sheshinski, E., 1998. Resilience in natural and socioeconomic systems. Environment and Development Economics. 3, 221-262.

Martin, C.J., 2016. The sharing economy: A pathway to sustainability or a nightmarish form of neoliberal capitalism? Ecological Economics. 121, 149-159.

McHugh, M., 2016. Special Commission of Inquiry into the Greyhound Racing Industry in New South Wales: Report Volume 1, State of NSW, Sydney.

Meadows, D.H., 2008. Thinking in systems: a primer. Chelsea Green Publishing Company, White River Junction.

Moffat, K., Lacey, J., Zhang, A., Leipold, S., 2016. The social licence to operate: a critical review. Forestry. 89, 477-488.

Moffat, K., Zhang, A., 2014. The paths to social licence to operate: An integrative model explaining community acceptance of mining. Resources Policy. 39, 61-70.

Morrison, J., 2014. The social licence: how to keep your organization legitimate. Palgrave Macmillan, Basingstoke.

Murillo, D., Buckland, H., Val, E., 2017. When the sharing economy becomes neoliberalism on steroids: Unravelling the controversies. Technological Forecasting and Social Change. 125, 66-76. 
O'Brien, J., Gilligan, G., Roberts, A., McCormick, R., 2015. Professional standards and the social licence to operate: a panacea for finance or an exercise in symbolism? Law and Financial Markets Review. 9, 283-292.

Owen, J., Kemp, D., 2012. Social licence and mining: acritical perspective. Resources Policy. $38,29-35$.

Parguel, B., Lunardo, R., Benoit-Moreau, F., 2017. Sustainability of the sharing economy in question: When second-hand peer-to-peer platforms stimulate indulgent consumption. Technological Forecasting and Social Change. 125, 48-57.

Parsons, R., Lacey, J., 2012. "Maintaining discursive legitimacy of a contested practice: how the Australian minerals industry understands its SLO”, Proceedings of the 5th Australasian Caucus of the Standing Conference on Organisational Symbolism, Melbourne, Australia.

Penz, E., Hartl, B., and Hofmann, E. (2018). Collectively Building a Sustainable Sharing Economy Based on Trust and Regulation. Sustainability. 10, 3754.

Prime Minister of Australia, 2016. "Doorstop: 3 August 2016". https://www.pm.gov.au/media/2016-08-03/doorstop. Accessed: 22 November 2016, Last updated: Unknown

Prno, J. (2013). An analysis of factors leading to the establishment of a social licence to operate in the mining industry. Resources Policy. 38(4), 577-590.

Prno, J., Slocombe, D., 2014. A Systems-Based Conceptual Framework for Assessing the Determinants of a Social License to Operate in the Mining Industry. Environmental Management. 53, 672-689.

Roth, G., 2011. "Retaining the social licence: the Australian cotton industry case study", in: Martin, P., Williams, J. (Eds.), Defending the Social Licence of Farming: Issues, 
Challenges and New Directions for Agriculture. CSIRO Publishing, Melbourne, pp. 69-83.

Schor, J., 2016. Debating the Sharing Economy. Journal of Self-Governance and Management Economics. 4, 7-22.

Schor, J., Fitzmaurice, C., Carfagna, L.B., Attwood-Charles, W., Poteat, E.D., 2016. Paradoxes of openness and distinction in the sharing economy. Poetics. 54, 66-81.

Sigala, M., 2017. "Market formation in the sharing economy: Findings and implications from the sub-economies of Airbnb”, in: Barile, S., Pellicano, M., Polese, F. (Eds.), Social dynamics in a systems perspective. Springer International Publishing AG, Geneva, pp. 159-174.

SMH, 2018. "Big tech's bad week has made the world wake up". https://www.smh.com.au/national/big-tech-s-bad-week-has-made-the-world-wakeup-20180323-p4z5uu.html. Accessed: 4 April 2018 2018, Updated: 23 March 2018

Stanford, J., 2017. The resurgence of gig work: Historical and theoretical perspectives. The Economic and Labour Relations Review. 28, 382-401.

Suchman, M. C., 1995. Managing legitimacy: Strategic and institutional approaches. Academy of Management Review. 20(3), 571-610.

The Senate Education and Employment References Committee, 2017. Corporate avoidance of the Fair Work Act 2009, Commonwealth of Australia, Canberra.

Thompson, K., Clarkson, L., Rebbeck, M., 2018. Too hot to trot? How horse owners in Australia have responded to major weather events. Rural Society. 27, 52-65. 
Thomson, I., Boutilier, R., 2011. "The social license to operate”, in: Darling, P. (Ed.), SME mining engineering handbook (3rd ed.). Englewood, Colorado: Society for Mining, Metallurgy, and Exploration. pp. 1779-1796.

Transport for London, 2017. "Licensing decision on Uber London Limited". https://tfl.gov.uk/info-for/media/press-releases/2017/september/licensing-decisionon-uber-london-limited. Accessed: 2 November 2017, Updated: 22 September 2017

UnionsNSW, 2016. Innovation or Exploitation: Busting the Airtasker Myth, UnionsNSW, Sydney.

Vargo, S., Lusch, R., 2017. Service dominant logic 2025. International Journal of Research in Marketing. 34, 46-67.

Voyer, M., Gladstone, W., Goodall, H., 2015. Obtaining a social licence for MPAs Influences on social acceptability. Marine Policy. 51, 260-266.

Walker, B., Holling, C.S., Carpenter, S.R., Kinzig, A., 2004. Resilience, adaptability and transformability in social-ecological systems. Ecology and Society. 9, 5.

Watanabe, C., Naveed, K., Neittaanmaki, P., Fox, B., 2017. Consolidated challenge to social demand for resilient platforms - Lessons from Uber's global expansion. Technol. Soc. $48,33-53$.

World Economic Forum, 2016. "How much is the sharing economy worth to GDP?". https://www.weforum.org/agenda/2016/10/what-s-the-sharing-economy-doing-togdp-numbers/. Accessed: 9 March 2018, Updated: 28 October 2016

Wüstenhagen, R., Wolsink, M., Bürer, M.J., 2007. Social acceptance of renewable energy innovation: An introduction to the concept. Energy Policy. 35, 2683-2691. 
Yaraghi, N., Ravi, S., 2017. The Current and Future State of the Sharing Economy, Brookings India IMPACT Series No. 032017.

Zhang, A., Moffat, K., Lacey, J., Wang, J., González, R., Uribe, K., Cui, L., Dai, Y., 2015. Understanding the social licence to operate of mining at the national scale: a comparative study of Australia, China and Chile. Journal of Cleaner Production. 108, Part A, 1063-1072. 